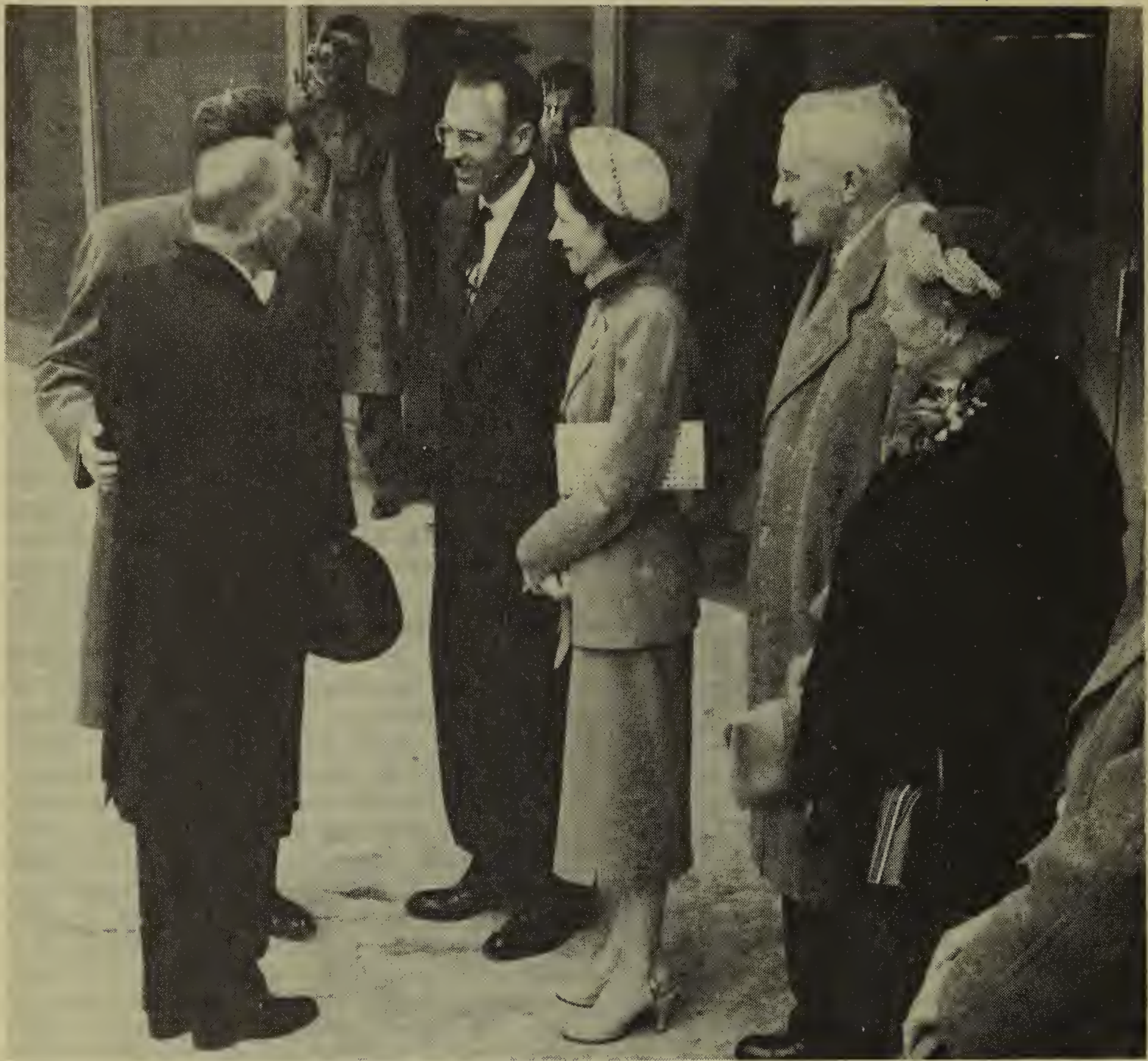

Mr. and Mrs. Fred Bradshaw are shown at the extreme right in this photo taken at the opening of the new Museum of Natural History on May 16, 1955. Mr. and Mrs. Fred Bard are being presented to the Governor General, Mr. Massey by the Hon. Mr. Brockelbank.

\title{
The Home of the Whooping Crane
}

\section{By FRED BRÁDSHAW}

To visit the home of the finest, tallest, and beyond question the most majestic bird of the American continent is a privilege that has fallen to the lot of few living persons. So far as I am aware, at this writing, I am the only living person who has had the good fortune to enjoy this most unusual experience. By a stroke of good fortune it was my pleasure to find, in 1922, the summer home of the Whooping Crane, Grus americana.

For many years, as Game Commissioner for the Province of Saskatchewan, I was charged with the administration of the Game Act.
While this work does not lend itself to an intensive study of birds and mammals, nevertheless, one who occupies such a position is compelled as a matter of course, to take more than a passing interest in wildlife conditions generally if he desires to deal intelligently with the various problems that from time to time confront him. It was in this way that I first became interested in the Whooping Crane; but it was not until January, 1922, upon learning that Dr. T. Gilbert Pearson, President of the National Association of Audubon Societies, Washington, D.C., had reported the finding of the winter 
feeding grounds of four of these birds in South Texas, and passed on the task of locating their summer home and safe keeping to Canada, that any serious attempt was made to carry out the line of work suggested.

Questionnaires sent out to over 400 correspondents in the early part of 1922 brought a few replies that warranted further investigation. Finally, our hopes of locating the breeding grounds of the Whooping Crane were centred around the area between the North and South Saskatchewan Rivers in the south western part of the province. I instructed Mr. Neil Gilmour, one of our Game Guardians, to investigate the lake a few miles south of Kerrobert. Here reports claimed that 12 Whooping Cranes lived in 1911 but these had dwindled to 2 in 1921. This pair had raised one young that year but two birds had been shot during the fall only 15 miles south of the breeding grounds. In spite of grave doubts, one pair made their appearance in 1922, built their home, and raised two young; our observer reported that so far as he was aware they all departed for the south unimpaired.

No sportman ever started out on a shooting trip with greater expectancy of thrills than I did on Saturday, May 28, 1922, when I set out to investigate the other prospect. A shot at these rare birds with my trusty cld 5 by 7 cartridge camera, antiquated though it be, would send the red blood tingling through my veins at a far greater velocity than would a shot from a death-dealing instrument of destruction, and there would be no twinge of remorse at having sent into oblivion one of the choicest cf the Creator's handiworks.

It was about 10 a.m. Sunday, May 29,1922 , when I arrived at a small farmhouse close to a little lake southwest of the village of Plenty. The kind occupants, at considerable inconvenience to themselves, agreed to tolerate my presence for a few days. I refused their kind invitation to accompany them to church, for I had just seen my first Whooping Cranes - three of them sailing over the marsh at no great distance from the house. Under the circumstances, I knew I could not concentrate on any man-made sermon, and without the slightest qualms of conscience I decided to commune with God and Nature under the canopy of the
Heavens on that beautiful Sabbath morn.

Donning my field apparel while a lunch of bulky proportions was prepared for me, I straightway headed for the north-east end of the large marsh where I had first seen the cranes flying. Imagine my chagrin when I could not find the birds! These long-legged, snow-white birds with fifty-inch perpendicular expansion should not be difficult to find with the aid of binoculars. I discovered about two hours later that my method of approach was altogether wrong. I was aimlessly walking around the marsh on the top of the bank above the horizon, thus exposing myself in full view and nary a glint did I get of the wary object of my search until I countered their hiding manoeuvres by dropping below the sky line. In bird hunting, it is often good policy to sit down and let the birds disclose themselves. This would be a good time to appease my hunger and dispose of the ample lunch I was carrying.

As I was finishing the delicious apple pie I caught sight of a white object in the brown-coloured marsh about one half mile straight in front of me. My binoculars were now focused on this Whooping Crane, for it was too far distant to observe clearly with the naked eye. Where was its mate? In all probability the birds were nesting, but where was one to look in all this expanse of marsh? Perhaps their nest was on the surrounding dry "land. After I had watched the bird feeding for forty.minutes, it rose and flew east a distance of about a hundred yards. Here it alighted and recommenced its feeding. Imagine my delight when, while watching these manoeuvres, I saw another white object close by which I instantly made out to be the neck of bird number two.

After a few minutes delay the feeding bird approached its mate; there was an occasional spreading of wings which made the bird in action very conspicuous, then one of the birds flew to where I had first noticed the feeding bird. I concluded that at last these wary birds had betrayed their regal home and that the antics I had witnessed were, perhaps, performed in the process of relieving the sitting bird. I adopted 
a slow but sure policy, waited about thirty minutes longer, and was treated to a recurrence of the events just related. Then I felt sure I was on the right track.

The next problem that confronted me was to find the nest, for it would be difficult to see far once I went down into the marsh. Fortunately there was a building on the other side of the marsh which I lined up with what I presumed to be the nesting site. By another stroke of luck there was a huge pile of bleached bones nearby. I placed cne pile on the top of the bank of the marsh in line with the nest and the building. Half way down the bank I placed another pile that now gave me a four point line which, if my calculations were right, would lead me to the nest. All I had to do was to keep looking back to see that the bone piles were in line.

On the way out the monotony of the trudge through shallow water was relieved by the discovery of a grebe colony of twenty or more nests. Some of the eggs were recently laid, chalky white, while others were dirty-looking and stained from the damp vegetation. The eggs were all covered, but I did not have the inclination to examine the colony any further just then. As I continued my unswerving progress the Whooping Cranes became a trifle uneasy and soon they separated going in opposite directions. I did not detour after either bird but continued my tiresome journey by the Bone Pile Route. I finally reached my destination without having to waver one iota from the line I had projected.

The nest was a huge structure similar in shape to that of a muskrat house made of a course three-sided sedge. It was from four to five feet in diameter at the base and stood about three feet above water level. It was dry on top and lined with a covering of finer grasses. Lying on this slightly hollowed hillock were three large eggs. Generally these birds lay only two eggs.

When the Whooping Cranes realized that I had discovered their nest they came closer and closer and with spread wings pretended many times, according to my interpretation, to be busily engaged at another nest. One bird circled twice within a hundred yards while I was taking a photograph of the nest. Not wishing to disturb the birds unduly and knowing the danger of arresting incubation if the eggs remained uncovered too long, I decided to call it a day.

The next day, bright and early, I started back by a shorter route. I had almost despaired of finding the nest when I was attracted by a pair of Pintail Ducks straining their necks to see what I was doing. I went toward them and to my great surprise I found them sunning themselves on the very nest I was looking fcr. As I was setting up the camera a sharp thunderstorm interrupted me. Later I noticed a strange piping whistle. This noise mystified me until I discovered that it came from a young crane who was just breaking through the shell. Fearing that the young bird might suffer if it did not receive immediate attention from its parents, which were now greatly perturbed, I ceased operations for the day. I was happy to have been in attendance at the Whooper's birth and to have taken photographs of this most unusual incident.

On the third day I approached the nest with caution. It was well that I did so, for scarcely had I come within sight of it when the young bird, which had hatched out by this time, scampered off the nest into the open water and had almost reached the margin of the dense marsh grasses when I caught it. Returning it to the nest I covered it with my hat unitil I was ready to take photographs. It was with difficulty that I got a photograph for it would insist upon stretching itself flat on the nest in a limp lifeless-looking form. Eventually it manifested a lively concern in its new world and the shutter clicked making a photographic record of Whooper Junior as he appeared on his birthday.

Because I had this thrilling experience with Whoopers in 1922 I have always been intensely interested in these huge birds. I was glad to read that six Whoopers, including young, were observed in the Wood Buffalo Park near the border of Northern Alberta and the Northwest Territories in 1955. I feel sure that the protective measures being put into effect by those interested in this crane will save it so that in the future many others may have the experience of seeing this magnificent bird. 